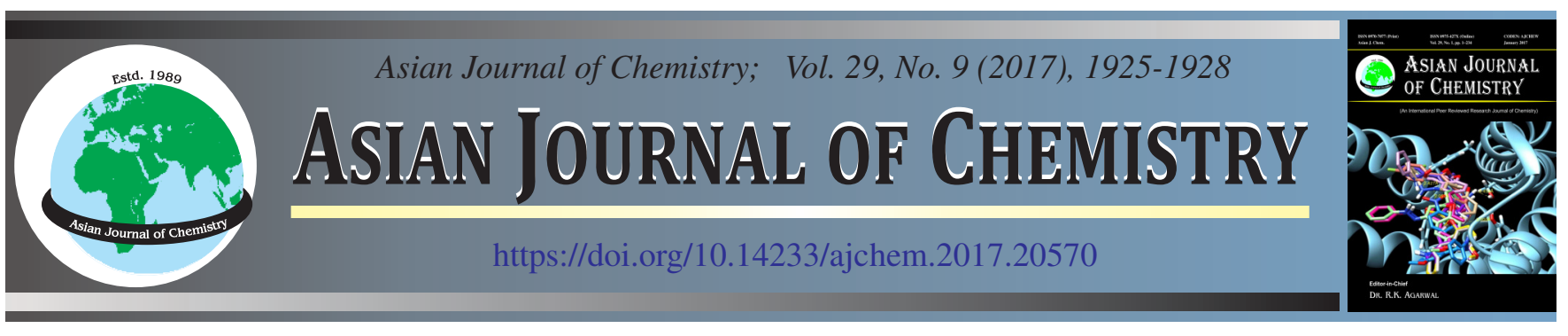

\title{
Photocatalytic Properties of Micro-Crystalline Polyoxometalate Synthesized Using Microemulsion Method
}

\author{
A. Arokia Nepolean Raj ${ }^{*}$ and T. Jeyabalan
}

Department of Chemistry, Sacred Heart College, Tirupattur-635 601, India

*Corresponding author: E-mail: nepneps@gmail.com

\begin{abstract}
In present study, a photocatalytic degradation of rhodamine-B by micro-crystalline polyoxometalates (POM) is investigated. The polyoxometalates catalyst is synthesized using microemulsion method and characterized by FT-IR, XRD and SEM. Photocatalytic degradation experiment is carried out in a setup by UV light irradiation in presence of catalyst and the degradation progress is evaluated using UV-visible spectrophotometer.
\end{abstract}

Keywords: Polyoxometalates, Microemulsion, Photocatalysis.

\section{INTRODUCTION}

The field of polyoxometalates (POMs) have been compelling research area in nanosized material world in recent years because they show large diversity in nuclearities size and shape $[1,2]$. Polyoxometalates are high-nuclearity architectures derived as negatively charged aggregates from transition metals of vanadium, molybdenum, tungsten and niobium in their highest oxidation states with oxygen in aqueous medium $[3,4]$. These compounds are cluster type with metal-oxygen and metal-oxygen-metal linkages with large number of lattice water in the interstitial position. Any element can be incorporated into the framework of polyoxometalates as heteroatoms. These large domains keep its application in medicine, catalysis and magnetism [5], etc., due to their amalgamation of value added properties of large size, high surface negative charge, redox properties, nucleophilicity and flexible structure [6]. Among the various polyoxometalates, the Waugh-type heteropolyanion have received greater significance in recent applications because it has biologically active site [7]. This Waugh-type is chiral 9-polyoxometalate having general structure $\left[\mathrm{XMo}_{9} \mathrm{O}_{32}\right]^{6-}$ where $\mathrm{X}$ is the central atom $\left(\mathrm{Mn}^{\mathrm{IV}}, \mathrm{Ni}^{\mathrm{IV}}\right)$ [8]. Parallel to these large clusters, the syntheses of nanosized polyoxometalates through organic based template has grown during last two decades due to their remarkable properities [9]. Microemulsion is one of the organic based templates which have expanded its hands towards nanoscale polyoxometalates. Microemulsions are isotropic, macroscopically homogeneous, transparent and thermodynamically stable solutions containing at least three components, namely water, oil and surfactant [10]. Reverse microemulsion based self-assembly of polyoxo-metalates is versatile method for its simplicity and reprodu-cibility with different morphology of nanostructures [11]. Herein, we report the synthesis of micro-structure of $\left(\mathrm{NH}_{4}\right)_{6}\left[\mathrm{MnMo}_{9} \mathrm{O}_{32}\right] \cdot \mathrm{nH}_{2} \mathrm{O}$ polyoxometalate having diamond like morphology using inverse microemulsion method in a single pot.

\section{EXPERIMENTAL}

Iso-octane, $n$-butanol, cetyltrimethyl ammonium bromide (CTAB), ammonium molybdate, manganese sulphate, hydrogen peroxide and rhodamine-B were purchased as commercial products from Merck Ltd. having analytical grade and used as such without any further purification. Aqueous solutions and microemulsion are prepared using doubly deionized water.

Analytical and physical methods: Scanning electron microscopy images were taken using Bruker AXS D8 Advance using $\mathrm{Cu}-\mathrm{K}_{\alpha}$ radiation $(\lambda=1.5406 \AA)$. An FT-IR spectrum was recorded using Perkin Elmer spectrum two spectrophotometer between the wave region 4000 to $400 \mathrm{~cm}^{-1}$ as $\mathrm{KBr}$ pellet.

Synthesis of $\left(\mathrm{NH}_{4}\right)_{6}\left[\mathrm{MnMo} \mathbf{O}_{32}\right] \cdot \mathbf{n H}_{2} \mathrm{O}$ nanocrystals: The bulk scale ammonium salt of titled compound has been prepared according to the literature [12] with slight modification. In typical preparation process of nanocrystals, the reverse microemulsion is prepared by molar ratio of $\mathrm{W}^{\circ}=12.5\left(\mathrm{~W}^{\circ}=\right.$ [water]/[surfactant]) which is shown in Fig. 1. An $18 \mathrm{~mL}$ of isooctane is stirred for $10 \mathrm{~min}$ with $5 \mathrm{~mL}$ of butanol in a very clean beaker. Then $5 \mathrm{~g}$ of CTAB is added with above mixture and dissolved completely under stirring for $15 \mathrm{~min}$ and the mixture becomes cloudy and little thick. Then $3 \mathrm{~mL}$ of deionized 
water $(5 \mathrm{~mL}, 0.2 \mathrm{~g})$ containing polyanion of $\left[\mathrm{MnMo}_{9} \mathrm{O}_{32}\right]^{6-}$ is added drop by drop into mixture under stirring. On addition of water, the cloudy mixture turned into clear transparent microemulsion. The transparent microemulsion is stirred for $1 \mathrm{~h}$. And then solid precipitating agent of ammonium nitrate of $2 \mathrm{~g}$ is added to transparent microemulsion slowly [13]. After another $1 \mathrm{~h}$ stirring, the orange coloured precipitate is formed in microemulsion. The orange coloured precipitate is collected by centrifugation at 2500 rotation/min for $20 \mathrm{~min}$ and washed many times with mixed solution of ethanol with water (ratio 1:05) to remove remaining organic contents. Finally, the orange coloured precipitate is dried at $40{ }^{\circ} \mathrm{C}$ for $24 \mathrm{~h}$ in vacuum oven.

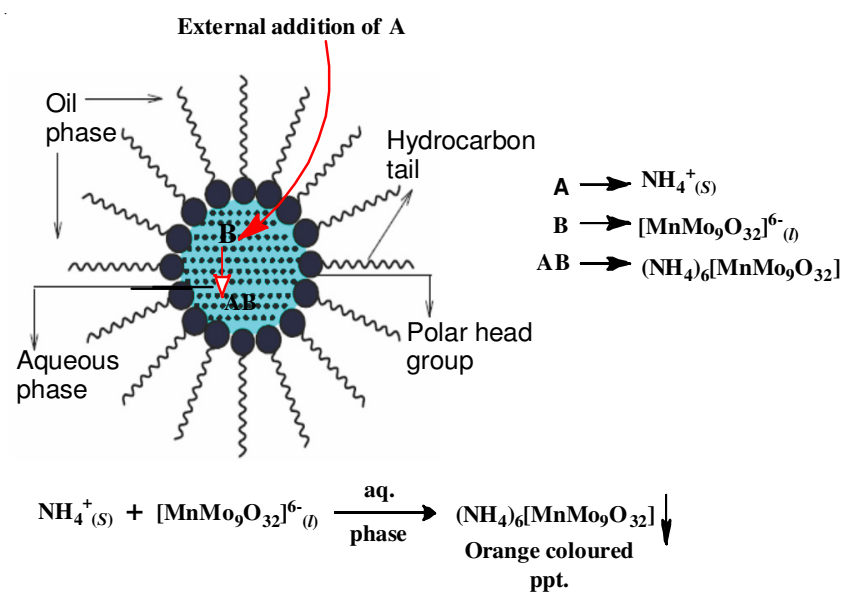

Fig. 1. A typical microemulsion reaction

Photocatalytic study: A photocatalytic experiment is carried out taking 1 ppm solutions of rhodamine-B as the model pollutant and the synthesized polyoxometalate as catalyst. The solutions are prepared by dissolving the required amount of rhodamine-B in distilled water. The photocatalytic degradation is performed in an UV cabinet fitted with an UV lamp and magnetic stirrer. During the experiments, $50 \mathrm{~mL}$ of $1 \mathrm{ppm}$ rhodamine-B solution, $0.01 \mathrm{~g}$ of the catalyst is added and stirred for $2 \mathrm{~h}$ to attain equilibrium condition and left for overnight adsorption. The test solution is exposed to short and middle UV light in a closed cabinet along with stirring and aeration. Samples for UV study is withdrawn every $30 \mathrm{~min}$ from the reaction mixture starting from $0 \mathrm{~min}$ to $150 \mathrm{~min}$. These test solutions are centrifuged, filtered and kept for characterization. Varian Cary 50 spectrophotometer is employed to study the degradation pattern. All the samples are scanned and collated between 450 to $650 \mathrm{~nm}$ range.

\section{RESULTS AND DISCUSSION}

FT-IR study: Infrared spectra of $\left(\mathrm{NH}_{4}\right)_{6}\left[\mathrm{MnMo}_{9} \mathrm{O}_{32}\right] \cdot \mathrm{nH}_{2} \mathrm{O}$ compound has recorded for micro and macro scale samples using $\mathrm{KBr}$ pellet in the range of $4000-400 \mathrm{~cm}^{-1}$ which shown in Fig. 2. The vibrational spectroscopy is a promising technique to ascertain the molecular skeleton of the polyoxometalates due to its unique and distinctive absorption of polyanion range. The stretching vibration of $\mathrm{v}(\mathrm{N}-\mathrm{H})$ in $\mathrm{NH}_{4}{ }^{+}$group is appeared at $3543 \mathrm{~cm}^{-1}$ and the bending vibration of $\delta(\mathrm{H}-\mathrm{N}-\mathrm{H})$ in $\mathrm{NH}_{4}{ }^{+}$ group is located at $1412 \mathrm{~cm}^{-1}$. These two vibrations of $\mathrm{NH}_{4}^{+}$ group appears both in micro and macro scale samples which

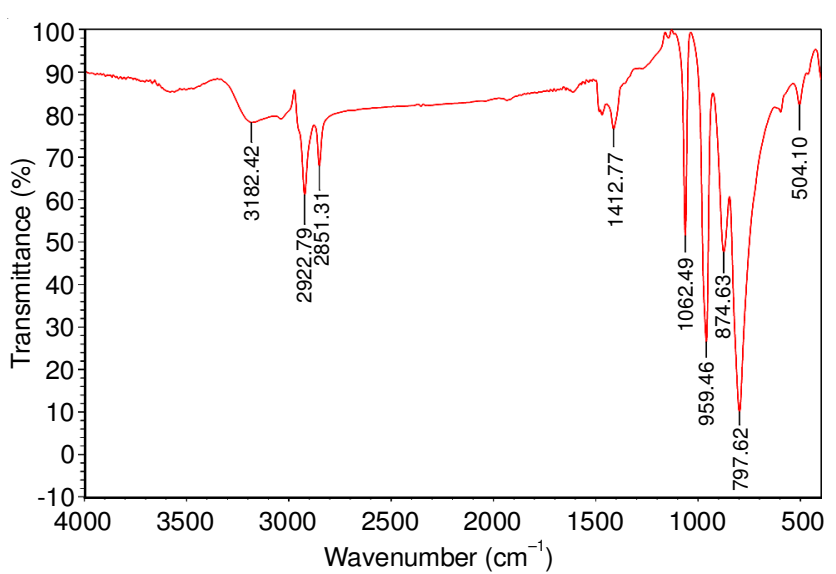

Fig. 2. IR spectra of $\left(\mathrm{NH}_{4}\right)_{6}\left[\mathrm{MnMo}_{9} \mathrm{O}_{32}\right] \cdot \mathrm{nH}_{2} \mathrm{O}$ micro and macro scale samples

assured one thing that the formation of the title compound in inverse microemulsion system is triggered by addition of solid precipitating agent not by surfactant molecules [14].

The stretching vibration of $\mathrm{v}(\mathrm{O}-\mathrm{H})$ in $\mathrm{H}_{2} \mathrm{O}$ group appear at $3182 \mathrm{~cm}^{-1}$ as a strong broad band confirmed that the presence of water molecules in lattice of the compound. The strong and medium sharp peak due to stretching vibrations of $\mathrm{v}(\mathrm{Mo}-\mathrm{O})$ are showed at 1062 and $959 \mathrm{~cm}^{-1}$ and these two absorption vibrations confirmed the linkage between molybdenum and oxygen. The bands at 874 and $797 \mathrm{~cm}^{-1}$ are attributed to bending vibrations of $\delta(\mathrm{Mo}-\mathrm{O}-\mathrm{Mo})$ and these bending vibrations reveals that octahedral edge sharing of compound. The medium sharp peak at $504 \mathrm{~cm}^{-1}$ is attributed to asymmetric stretching vibration of (Mn-O-Mo). The absorption bands of $\mathrm{v}(\mathrm{Mn}-\mathrm{O})$ and $\delta(\mathrm{Mn}-\mathrm{O}-\mathrm{Mo})$ are may possibly covered by $v(\mathrm{Mo}-\mathrm{O})$ and $\delta(\mathrm{Mo}-\mathrm{O}-\mathrm{Mo})$ [15]. Therefore, the infrared data confirms that the prepared compound both macro and nano scale level is $\left(\mathrm{NH}_{4}\right)_{6}\left[\mathrm{MnMo}_{9} \mathrm{O}_{32}\right] \cdot \mathrm{nH}_{2} \mathrm{O}$. heteropolyoxomolybdates.

Powder X-ray diffraction study: The powder X-ray diffraction study was recorded for the reverse microemulsion template based synthesized of $\left(\mathrm{NH}_{4}\right)_{6}\left[\mathrm{MnMo}_{9} \mathrm{O}_{32}\right] \cdot \mathrm{nH}_{2} \mathrm{O}$ heteropolyoxometalate. X-ray diffraction pattern of nanomaterial has been shown in Fig. 3. The X-ray pattern shows that the synthesized $\left(\mathrm{NH}_{4}\right)_{6}\left[\mathrm{MnMo}_{9} \mathrm{O}_{32}\right] \cdot \mathrm{nH}_{2} \mathrm{O}$ polyoxomolybdate from reverse microemulsion has well-structured crystalline structure and also reveals that the variation of size of microcrystals prepared through reverse microemulsion. This attribution of polyoxometalate has already confirmed through scanning electron micrograph which revealed that the formation diamond like nanocystals from reverse microemulsion template. The XRD pattern shows that the micro crystal has Rhombohedral shape in the space group R32, with $\mathrm{a}=\mathrm{b}=$ 15.681(2), $c=12.398(3) \AA, \alpha=\beta=90.00^{\circ}, \gamma=120.00^{\circ}, \mathrm{V}=$ 2640.2(7) $\AA^{3}, \mathrm{Z}=3, \mathrm{R}_{1}\left(\mathrm{wR}_{2}\right)=0.054(0.1302)$ [17] and in accordance with the XRD data base JCPDS No. 80-2182.

Scanning electron microscopic study: The inverse microemulsion system of water in oil is prepared by using CTAB, isooctane, water and butanol as a cosurfactant. The cationic surfactant of CTAB forms aggregates with water, in which the inner core is formed by the head groups and the chains form the outer surface. This is termed a water-in-oil droplet and act as a template for synthesis of nanocrystals. The exact size and shape of inverse microemulsion of above mentioned system 


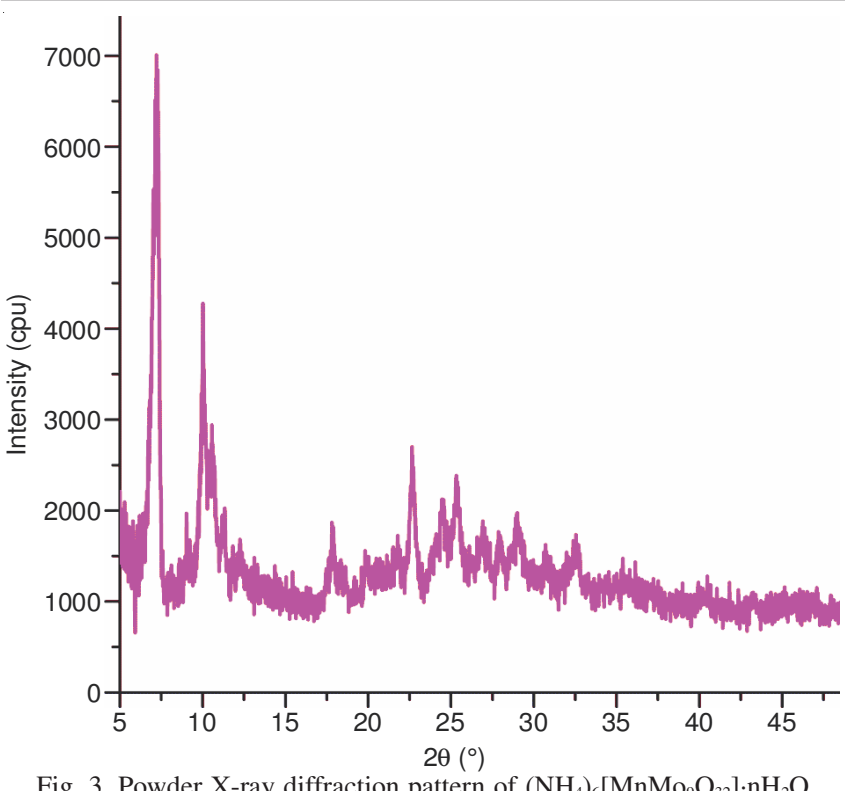

Fig. 3. Powder X-ray diffraction pattern of $\left(\mathrm{NH}_{4}\right)_{6}\left[\mathrm{MnMo}_{9} \mathrm{O}_{32}\right] \cdot \mathrm{nH}_{2} \mathrm{O}$

is unpredictable. However, there is rather large consensus that reverse micelles are good nanoreactors for obtaining spherical and cubic like nanomaterials [16].

The formation of diamond like morphology of $\left(\mathrm{NH}_{4}\right)_{6}\left[\mathrm{MnMo}_{9} \mathrm{O}_{32}\right]$ microcrystals have shown in SEM image (Fig. 4) in two different magnifications A and B. The formation of diamond like microcrystals are obtained by directly adding the solid precipitating agent of ammonium nitrate into template which containing polyanion of $\left(\mathrm{MnMo}_{9} \mathrm{O}_{32}\right)^{6-}$. The size of crystal depends on the size of the template that is size of aqueous pool. There is linear correlation between value of water content $\left(\mathrm{W}^{\circ}\right)$ and size of resulting nanocrystals. The size of diamond like microcrystals is varying from $0.5-3 \mu \mathrm{m}$, which indirectly implies that the size of aqueous part is varying due to dynamic motion and collision with other droplets of system.

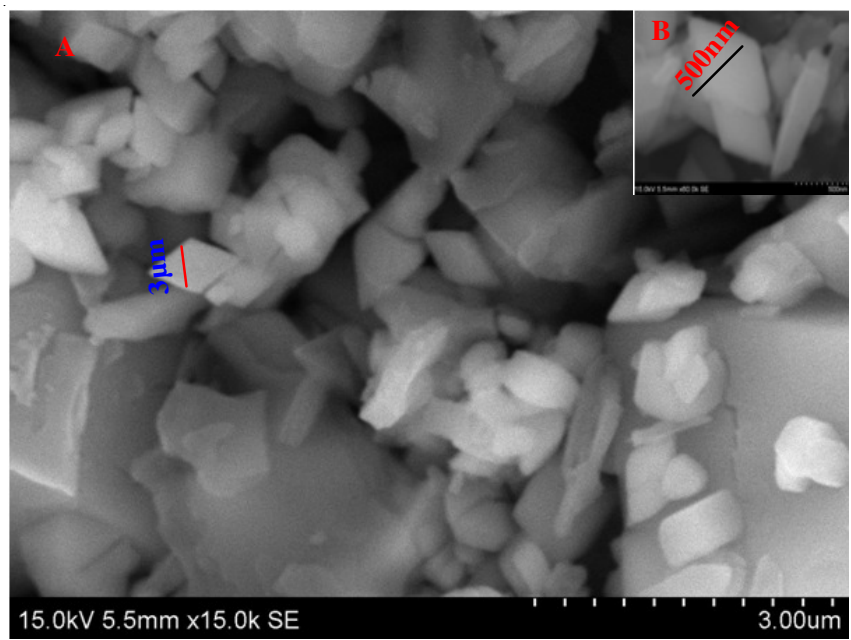

Fig. 4. SEM image of $\left(\mathrm{NH}_{4}\right)_{6}\left[\mathrm{MnMo}_{9} \mathrm{O}_{32}\right] \cdot \mathrm{nH}_{2} \mathrm{O}$ micro crystals

Photocatalytic degradation of rhodamine-B: The degradation of rhodamine-B by the influence of polyoxometalate has given good results shown in Fig. 5. The degradation of the dye is observed by following the absorbance at $552 \mathrm{~nm}$, which is the characteristic absorbance of rhodamine-B. The

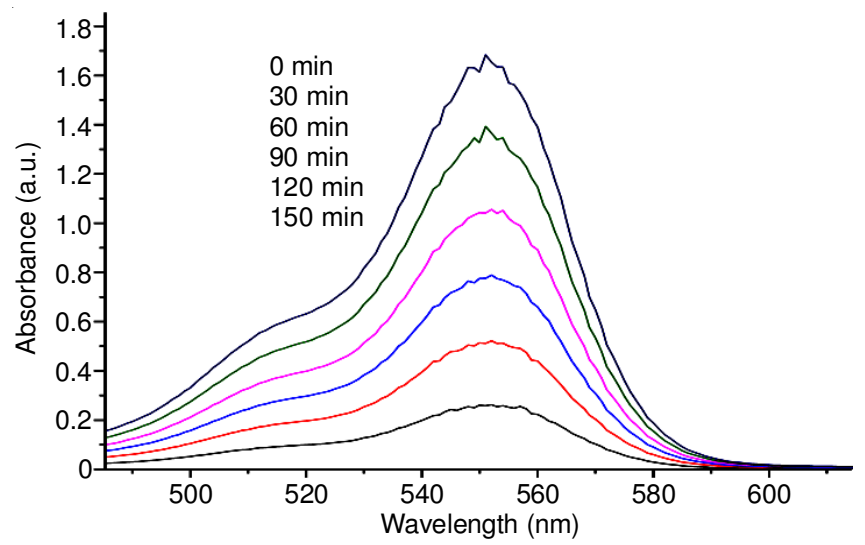

Fig. 5. Ultra violet spectra of rhodammine-B degradation with respect time by $\left(\mathrm{NH}_{4}\right)_{6}\left[\mathrm{MnMo}_{9} \mathrm{O}_{32}\right] \cdot \mathrm{nH}_{2} \mathrm{O}$ microcrystals

degradation was also visible to the naked eye by the colour change being observed as the reaction proceeds. a blank experiment was also conducted in the absence of catalyst for $2 \mathrm{~h}$ in which there is no significant degradation of the dye. After an illumination time of about $2 \mathrm{~h}$, rhodamine- $\mathrm{B}$ is completely degraded as colourless solution. The reaction mechanism in presence of polyoxometalate and oxygen include the following possible steps.

The Mo which is in +6 oxidation state that is $d^{0}$ configuration in the Waugh structure which is in the ground state is excited by UV light. The oxygen present in the air (from purge) is utilized by charge transfer to the Mo transition metal in $d^{0}$ state $[18,19]$. The micro scale and partially nanoscale of the $\left(\mathrm{NH}_{4}\right)_{6}\left[\mathrm{MnMo}_{9} \mathrm{O}_{32}\right] \cdot \mathrm{nH}_{2} \mathrm{O}$ synthesized shows increased surface area which in turn creates more contact areas between the catalysts and substrates which promotes surface mediated electron transfer reactions. This surface mediated electron transfer helps to degrade the rhodamine-B more effectively in a given time. The rhodamine-B degrades more than $50 \%$ in 90 min indicates that there is surface mediated electron transfer from oxygen to Mo [20-23]. Another mechanism is as suggested by Hiskia \& Papaconstantinou [25] and Neumann \& Levin [26] suggestion can be applied to Mo atom. The dioxygen atom coordinates to Mo to form distorted seven coordinated Mo center structure. Further the formed distorted structures undergo electron transfer from Mo to the coordinated dioxygen and this leads to formation Mo-superoxide radical. The formed Mo-superoxide radical again undergoes electron transfer by inner sphere mechanism, which leads to formation of $\mathrm{H}_{2} \mathrm{O}_{2}$ [24-26]. The formation of Mo-superoxide and $\mathrm{H}_{2} \mathrm{O}_{2}$ degrades the Rh-B dye effectively.

\section{Conclusion}

Microemulsion method is successfully employed to synthesize polyoxometalate in microscale. The diamond shaped and rhombohedral micro crystal of polyoxometalate is characterized using FT-IR, XRD, SEM and the paticle size obtined to the extent $500 \mathrm{~nm}$. The heterogenous particle size ranging from nano meter to few micro meter were reported, which gave pomising results in photodegradation of rhodamine$\mathrm{B}$ which is taken as model polutatnts. The rhodamine-B degrades more than $50 \%$ in 90 min indicates there is surface mediated electron transfer from oxygen to metal which in turn 
produced hydrogen peroxide involved in the degradation process. Research work may also be extended to other dyes and other polyoxometalates in nano scale.

\section{ACKNOWLEDGEMENTS}

The authors acknowledge to UGC-SERO, for financial assistance and APRC Sacred Heart College for providing the facilities for research.

\section{REFERENCES}

1. W. Guo, H. Lv, Z. Chen, K.P. Sullivan, S.M. Lauinger, Y. Chi, J.M. Sumliner, T. Lian and C.L. Hill, J. Mater. Chem. A Mater. Energy Sustain., 4, 5952 (2016);

https://doi.org/10.1039/C6TA00011H.

2. A. Dolbecq, E. Dumas, C.R. Mayer and P. Mialane, Chem. Rev., 110, 6009 (2010); https://doi.org/10.1021/cr1000578.

3. D.-L. Long, E. Burkholder and L. Cronin, Chem. Soc. Rev., 36, 105 (2007); https://doi.org/10.1039/B502666K

4. Y. Wang and I.A. Weinstock, Chem. Soc. Rev., 41, 7479 (2012); https://doi.org/10.1039/c2cs35126a.

5. M.T. Pope and A. Muller, Polyoxometalates: From Platonic Solids to Anti-Retroviral Activity, Kluwer Academic Publishers: Dordrecht, Netherlands (1994).

6. M.T. Pope, Heteropoly and Isopoly Oxometalates, Springer-Verlag, New York (1983)

7. R.R. Crichton, Biological Inorganic Chemistry, Elsevier, Amsterdam, vol. 1, p. 271 (2008)

8. M. Dahal and G.L. Lawrance, Inorg. React. Mech., 5, 117 (2003).

9. X.H. Zhang, S.Y. Xie, Z.Y. Jiang, L.C. Zhou, Z.X. Xie, R.-B. Huang and L.-S. Zheng, Chem. Commun., 2032 (2002); https://doi.org/10.1039/B205089G

10. J.H. Schulman, W. Stoeckenius and L.M. Prince, J. Phys. Chem., 63 1677 (1959);

https://doi.org/10.1021/j150580a027.
11. D.L. Long and L. Cronin, Chem. Eur. J., 12, 3698 (2006); https://doi.org/10.1002/chem.200501002.

12. L.C.W. Baker and T.J.R. Weakley, J. Inorg. Nucl. Chem., 28, 447 (1966); https://doi.org/10.1016/0022-1902(66)80324-X

13. M.A. Lopez Quintela, Curr. Opin. Colloid Interface Sci., 8, 137 (2003); https://doi.org/10.1016/S1359-0294(03)00019-0.

14. A.A. Nepolean Raj and T. Jeyabalan, J. Chem. Chem. Sci., 4, 43 (2014).

15. S. Lin, Y. Zhen, S.-M. Wang and Y.-M. Dai, J. Mol. Catal. A, 156, 113 (2000); https://doi.org/10.1016/S1381-1169(99)00414-8.

16. M.P. Pileni, Nat. Mater, 2, 145 (2003); https://doi.org/10.1038/nmat817.

17. L.Y. Feng, Y.H. Wang, Y.J. Qi, C.W. Hu, Y. Xu and E.B.J. Wang, Mol. Str., 645, 231 (2003); https://doi.org/10.1016/S0022-2860(02)00582-3.

18. S.-S. Wang and G.-Y. Yang, Chem. Rev., 115, 4895 (2015); https://doi.org/10.1021/cr500390v.

19. Y.H. Guo and C.W. Hu, J. Mol. Catal. A, 262, 136 (2007) https://doi.org/10.1016/j.molcata.2006.08.039.

20. E. Papaconstantinou, Chem. Soc. Rev., 18, 1 (1989); https://doi.org/10.1039/cs9891800001.

21. M. Bonchio, M. Carraro, G. Scorrano, E. Fontananova and E. Drioli, Adv. Synth. Catal., 345, 1119 (2003); https://doi.org/10.1002/adsc.200303076.

22. S. Farhadi, M. Afshari, M. Maleki and Z. Babazadeh, Tetrahedron Lett., 46, 8483 (2005); https://doi.org/10.1016/j.tetlet.2005.10.019.

23. A. Troupis, A. Hiskia and E. Papaconstantinou, Angew. Chem. Int. Ed., 41, 1911 (2002); https://doi.org/10.1002/1521-3773(20020603)41:11<1911::AIDANIE1911>3.0.CO;2-0.

24. C. Chen, J. Zhao, P. Lei, J. Zhao and N. Serpone, Chem. Eur. J, 10, 1956 (2004); https://doi.org/10.1002/chem.200305453.

25. A. Hiskia and E. Papaconstantinou, Inorg. Chem., 31, 163 (1992); https://doi.org/10.1021/ic00028a007.

26. R. Neumann and M. Levin, J. Am. Chem. Soc., 114, 7278 (1992); https://doi.org/10.1021/ja00044a044. 